\section{THE ROAD TO GENDER EQUITY IN SURGERY IS LONG}

This is a response to the article, "A solution to gender inequity in surgery? Better caregiving policies" by Acai and colleagues. ${ }^{1}$ Their discussion of how caregiving responsibilities and institutional caregiving policies can deter a junior trainee's desire to enter a surgical specialty is clear and compelling. Furthermore, the suggestion that better caregiving policies can help solve the issue of gender inequity in surgery (and in medicine broadly) is timely. However, the issue of gender inequity in surgery is multifactorial, and we argue that the design of caregiving policies is a symptom of gender inequity, rather than a cause. Therefore, like treating an illness, solving gender inequity in surgery (and in medicine, broadly) requires more than addressing the symptoms. Are women more likely to choose a career in surgery if they are afforded adequate parental leave in the future? We argue that it would probably help, but would likely be insufficient, unless the underlying cause of gender bias and inequity is addressed.

As obstetricians and gynecologists, we are in the somewhat unique position of representing a surgical specialty that is currently dominated by female trainees. ${ }^{2}$ Our specialty has similar caregiving policies and constraints in both training and practice; however, we have been able to recruit female medical students with great success. We do not, however, believe that gender balance equates with gender equity in obstetrics and gynecology, or any other field. Rather, we recognize that intimidation and harassment, glass ceilings, and differential treatment exist, and this is supported in the literature. $^{3-6}$ To solve the problem of gender inequity in surgery and in medicine, we must address the root causes in addition to the symptoms. This is obviously more challenging.
We know, primarily from research in the social sciences, that gender bias is related to traditional sex-role stereotypes that persist in society. These stereotypes can influence the perception and expectations of men and women in the workplace. ${ }^{7}$ Historically in medicine, most women took on nonphysician roles, such as nursing, which mirrored their traditional caregiving role in the home. ${ }^{8}$ This was in keeping with sex-role stereotypes, which described women as communal (i.e., caring and empathic), and men as agentic (i.e., competent, powerful). ${ }^{7}$ These roles can frame our expectations and evaluation of behaviour exhibited by women and men, producing some of the symptoms of gender inequity. ${ }^{7}$ Therefore, we can conceptualize current caregiving policy as a symptom of traditional gender-based power inequity that has persisted in the health professions. Policies and policy-makers have consciously or unconsciously undervalued childcare, labelling it as "women's work," and, consequently, created a situation that fails to accommodate women (or childcare providers of any gender) in the workplace.

One potential solution is to engage the entire profession in critical reflection about our assumptions and biases pertaining to expectations of men and women as surgeons, physicians and members of a society that values families. The aim is to catalyze constructive conversations about the structure of our institutions: who benefits, who doesn't, and why? Only then can we begin to understand and mitigate the root causes of gender inequity. A better caregiving policy is a step in the right direction, but the road is long. We need to ensure that this step and others we might take lead to a situation where equity is the cultural norm.

Evan Tannenbaum, MD, MSc; Michele Farrugia, MD, MEd
Affiliations: From the Department of Obstetrics and Gynaecology, University of Toronto, Toronto, Ont. (Tannenbaum, Farrugia); and the Department of Obstetrics and Gynaecology, Sinai Health System, Toronto, Ont. (Farrugia).

Competing interests: None declared.

DOI: 10.1503/cjs.1962301

\section{References}

1. Acai A, Steyn C, Reid SE, et al. A solution to gender inequity in surgery? Better caregiving policies. Can 7 Surg 2018;61:6-7.

2. Brandt JS, Kramer SE, Chasen ST. Academic differences among male and female candidates applying for obstetrics and gynecology residency: the experience of one program. F Surg Educ 2013;70:439-42.

3. Hill EK, Blake RA, Emerson JB, et al. Gender differences in scholarly productivity within academic gynecologic oncology departments. Obstet Gynecol 2015;126:1279-84.

4. Peel JK, Schlachta CM, Alkhamesi NA. A systematic review of the factors affecting choice of surgery as a career. Can 7 Surg 2018;61:58-67.

5. Esteves-Sorenson C, Snyder J. The gender earnings gap for physicians and its increase over time. Econ Lett 2012;116:37-41.

6. Galvin SL, Parlier AB, Martino E, et al. Gender bias in nurse evaluations of residents in obstetrics and gynecology. Obstet Gynecol 2015;126:7S-12S

7. Eagly AH, Karau SJ. Role congruity theory of prejudice toward female leaders. Psychol Rev 2002;109:573-98.

8. Witz A. Patriarchy and professions: the gendered politics of occupational closure. Sociology 1990;24:675-90.

\section{AUtHOR RESPONSE TO "THE ROAD TO GENDER EQUITY IN SURGERY IS LONG"}

We wish to thank Drs. Tannenbaum and Farrugia for their thoughtful response to our commentary.

We fully agree that gender inequity in surgery (and many other professions) is a complex, multifactorial issue. We too would like to see the root causes of the issue redressed. However, we suggest that the distinctions between symptoms and causes are often blurry. 